\title{
СТВОРЕННЯ БЛОКУ ВИМІРУ ЧАСТОТИ ДЛЯ ДОППЛЕРІВСЬКОГО УЛЬТРАЗВУКОВОГО ВИТРАТОМІРА
}

\author{
Зубков С. В., ст. вик \\ szub284@gmail.com \\ Феч $0.0 .$, студент \\ ardn@meta.ua \\ Факультет біомедичної інженерії \\ Національний технічний університет \\ «Київський політехнічний інститут імені Ігоря Сікорського» \\ м. Київ, Україна
}

\begin{abstract}
Реферат - Одним з показників стану гемодинаміки людини є швидкість кровотоку в судинах. Показник швидкості кровотоку залежить від частоти скорочень сериевого м'яза, кількості і якісного складу крові, величини судин, артеріального тиску, віку і генетичних особливостей організму. На даний час у діагностиці широкого розповсюдження набув метод ультразвукової допплерографії. Але, оскільки отриманий за допомогою допплерівського вимірювача швидкості сигнал $\epsilon$ спектром частот, то актуальним є питання створення блоку виміру частоти для кількісної оцінки стану гемодинаміки.У даній роботі розглядається створення та моделювання блоку вимірювання частоти, яка прачює на частотах від 200 до 20000 Ги, напруга живлення якої 15 В, діапазон значень від 6 до 1,27 В.
\end{abstract}

Ключові слова - ефект Допплера, частотомір, швидкість кровотоку, ультразвук, флоуметрія, допплерографія, МісгоСар, гемодинаміка.

\section{I. ВСТУП}

Одним $з$ показників стану гемодинаміки людини $\epsilon$ швидкість кровотоку в судинах. Показник швидкості кровотоку залежить від частоти скорочень серцевого м'яза, кількості і якісного складу крові, величини судин, артеріального тиску, віку i генетичних особливостей організму. На даний час у діагностиці широкого розповсюдження набув метод ультразвукової допплерографії. Але, оскільки отриманий за допомогою допплерівського вимірювача швидкості сигнал $\epsilon$ спектром частот, то актуальним $\epsilon$ питання створення блоку виміру частоти для кількісної оцінки стану гемодинаміки.

\section{II. ОГЛЯД ЛІТЕРАТУРИ}

Найпростіший допплерівський ультразвуковий вимірювач швидкості безперервного випромінювання був розроблений у 1957 році Сатомурою [1]. У ньому підсилений сигнал 3 приймача перемножується 3 сигналом генератора i формує сигнал, високочастотна складова якого не несе інформації про допплерівський зсув частот i може бути відфільтрована фільтром низьких частот.
Отриманий після фільтрації сигнал $\epsilon$ спектром, вклад в який вносять не лише формені елементи крові, але й інші структури, які можуть мати низькочастотні допплерівські зміщення (рух стінок судин) [2], тому $\epsilon$ необхідність у створенні додаткового фільтра високих частот.

Для отримання кількісної інформації про кровоток необхідний перетворювач частоти у напругу [3], для чого використовують детектори.

Частотомір це прилад електровимірювання, що використовуються для фіксації частоти періодичного процесу або частот гармонійних складових спектру сигналу.

За методом виміру частоти частотоміри поділяють на:

- аналогові, які призначені для оцінки частоти;

- прилади порівняння, до яких відносяться резонансні, гетеродинні, електронно-обчислювальні пристрої, тощо.

Принцип роботи конденсаторних частотомірів заснований на явищах заряду і розряду конденсаторів, що співпадає 3 частотою вхідного сигналу. 
Гетеродинний частотомір працює за рахунок порівняння частоти вхідного сигнала 3 частотою гетеродина (генератора).

Резонансні частотоміри, подібно до гетеродинних, порівнюють частоту вхідного сигналі із частотою резонансного коливального контуру.

Електронно-лічильний частотомір рахує кількість імпульсів, що формуються вхідними ланцюгами 3 періодичного сигналу довільної форми. При цьому інтервал часу рахунки задається кварцевим генератором.

Робота аналогових частотомірів заснована на перетворенні однакових сформованих імпульсів у значення напруги та безпосередньому вимірі цього значення.

\section{META}

Проектування вузла виміру частоти для ультразвукового допплерівського вимірювача швидкості крові безперервного випромінювання.

\section{IV. МАТЕРіАЛИ}

Моделювання проводилося в програмному забезпеченні МicroСap 9[4], створення схеми друкованої плати виконано за допомогою програмного забезпечення DipTrace [5].

\section{V. РЕЗУЛЬТАТИ ТА ОБГОВОРЕННЯ}

Основуючись на даних літературних джерел [6,7], а також розглянутих методах $[8,9]$ виміру частоти, було створено структурна схему одиничного каналу блоку виміру частоти (рисунок 1).

Вона включає наступні блоки:

- блок формування прямокутних імпульсів;

- блок формування імпульсів постійної тривалості;

- блок фільтрації та підсилення.

Вхідний сигнал та живлення надходять 3 приладу вимірювання швидкості кровотоку та джерела. Вихідний сигнал подається на вимірювач напруги.

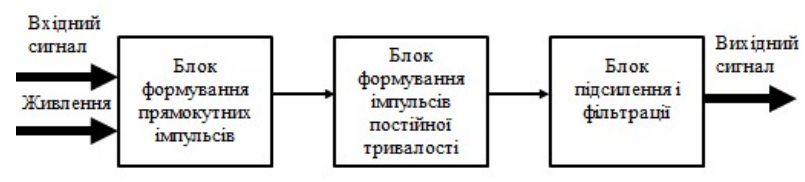

Puc. 1 Структурна схема вимірювача частоти
Функціональна схема (рисунок 2) вузла виміру частоти містить два канали для сигналу прямого і зворотного кровотоку, які виділяються у приладі за допомогою схеми квадратурної демодуляції.

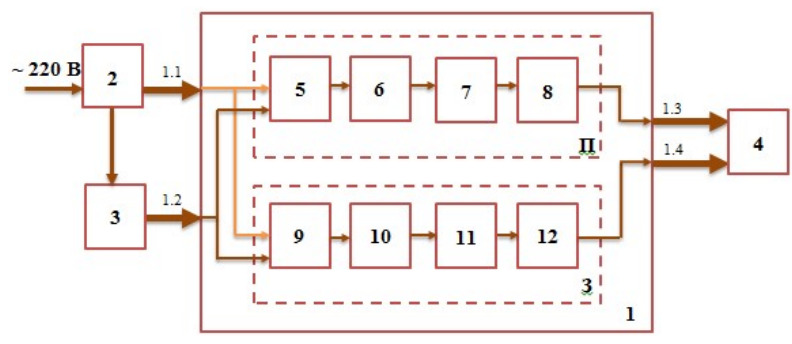

Puc. 2 Функціональна схема вузла виміру частоти

У даній схемі: 1 - вузол вимірювання частоти; 2 - блок живлення; 3 - блок обробки сигналу; 4 - вимірювач напруги; 1.1 - жгут для під'єднання до джерела живлення; 1.2 жгут для під'єднання до джерела сигналу; 1.3, 1.4 - жгути для під'єднання до вимірювача напруги каналів прямого i зворотного кровоточу; П - канал прямого кровоточу; 3 канал зворотного кровоточу; 5, 9 - ключ; 6, 10 - тригер Шмітта; 7,11 - мультивібратор; 8,12 фільтр 3-го порядку, який складатиметься 3 інтегратору та ФНЧ другого порядку СаленаКея.

Відповідна принципова електрична схема аналогового вимірювача частоти створена у середовищі МicroСap 9 (рисунок 3).

Вхідний сигнал моделюється за допомогою джерела сигналу синусоїдальної форми V1. У даній схемі використовується однополярне живлення. Джерелами живлення на 15 вольт є $\mathrm{V} 2$ та V3.

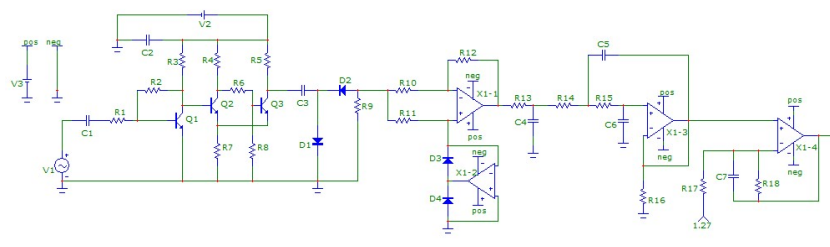

Puc. 3 Принципова електрична схема вимірювача частоти

Розглянемо схему за функціональними блоками. Конденсатор С1 необхідний для відсікання постійної складової вхідного сигналу. Конденсатор С2 слугує для шунтування живлення мікросхеми. Резистор R1 - опір бази транзистора Q1, резистор R3, відповідно, - опір його колектора. Перший каскад на транзисторі Q1 необхідний для 
створення прямокутних імпульсів і працює як ключ із заданим порогом спрацьовування, що досягається завдяки резистору R2.

Після нього сигнал потрапляє на тригер Шмітта, що реалізований на двох біполярних транзисторах Q2 та Q3, а також за допомогою резисторів R4-R8. Тригер Шмітта перетворює прямокутні імпульси, що надходять 3 ключа, на такі, що мають стабільну амплітуду, яка не залежитиме від інтенсивності сигналу. Оскільки під час систоли кількість еритроцитів збільшується, то i амплітуда сигналу, що подається на вхід частотоміра, теж збільшується, що вносить похибку у роботу схеми.

Крім того, від амплітуди вхідного сигналу буде залежити тривалість імпульсів, що неможливо подолати за допомогою лише тригера Шмітта, тому далі сигнал надходить до чекаючого мільтивібратора. Він виконаний за допомогою конденсатора C3, резистора R9 та двох діодів D1, D2. При розряді конденсатора C3 через випрямляючі діоди D1, D2 формуються стабільні за амплітуда та тривалістю від'ємні пікоподібні імпульси. Вони надходять до двопівперіодного випрямляча, який виконаний на базі двох операційних підсилювачів X1-1 та X1-2, двох діодів D3, D4, та резисторів R10, R11, R12. Випрямляч працює таким чином, що при надходженні позитивної напівхвилі має коефіцієнт підсилення рівний одиниці, а при надходженні негативної напівхвилі вихідний сигнал інвертований (рисунок 4).

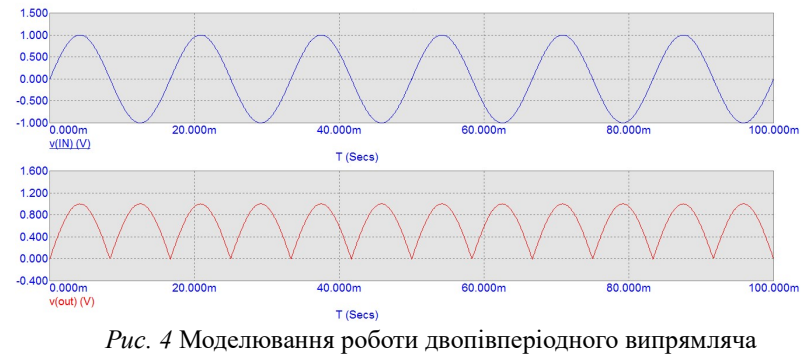

Таким чином вся робота блоку формування імпульсів може бути розглянута за допомогою часових діаграм на рисунку 5, де $\mathrm{v}(1)$ вхідний сигнал, v(4) - сигнал після ключа, $\mathrm{v}(11)$ - сигнал після чекаючого мультивібратора, v(14) - сигнал після двопівперіодного випрямляча.

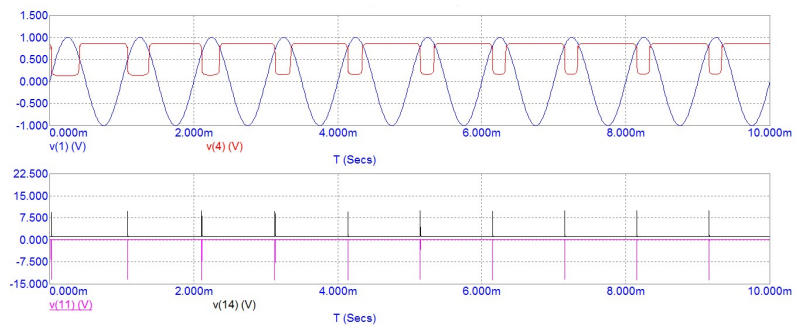

Puc. 5 Часові діаграми блоку формування імпульсів

Після того, як імпульси сформовані, вони надходять до інтегратору, що складається 3 конденсатору C4 та резистору R13, а також до фільтра низьких частот другого порядку, побудованого за схемою Салена-Кея. Він складається 3 резисторів R14- R16, конденсаторів C5, C6 та операційного підсилювача X1-3.

Логарифмічна амплітудно-частотна характеристика ФНЧ та інтегратора зображена на рисунку 6.

Оскільки отриманий діапазон амплітуд вихідного сигналу доволі вузький, застосований підсилювач на базі операційного підсилювача X1-4, резисторів R17, R18 та конденсатору C7, який разом із R17 утворює фільтруючу ланку.

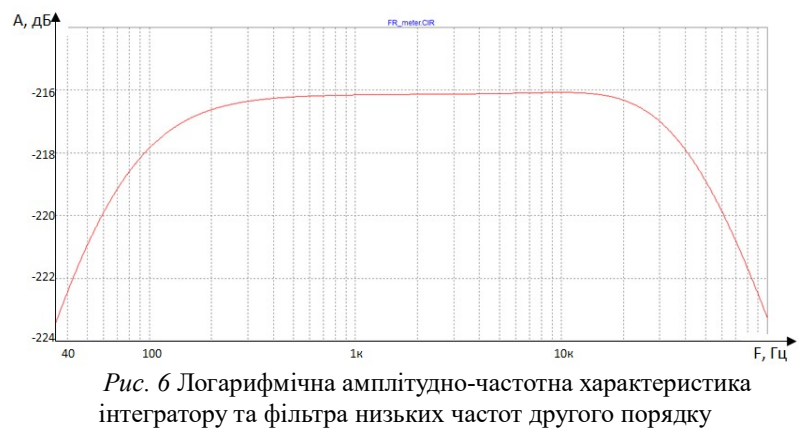

Для моделювання поведінки схеми на різних частотах в межах робочого діапазону було створено тестовий синусоїдний сигнал тривалістю 0,6 секунди, що включає в себе наступні частоти: 20кГц, 10кГц, 5кГц, 2.5кГц,

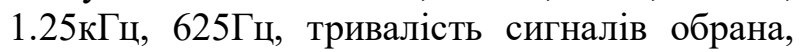
виходячи зі значення тривалості перехідного процесу схеми.

На рисунку 7 зображений вигляд подібного сигналу зі скороченою тривалістю. 


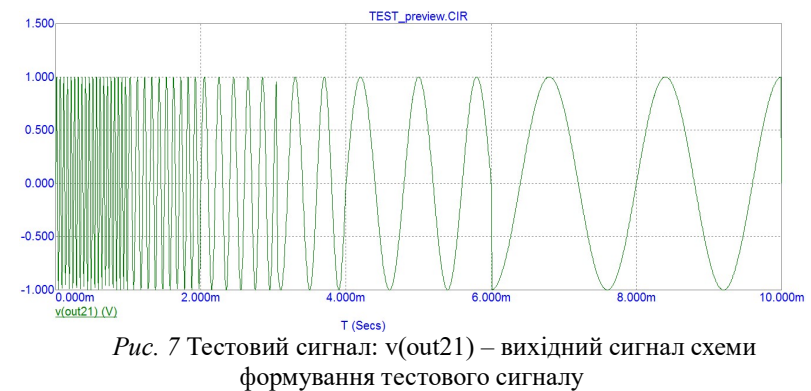

Після подання тестового сигналу на вхід схеми вимірювання частоти були отримані значення напруги на виході (рисунок 8).

Перехідний процес даної схеми триває близько 80 мсек, зміна частоти тестового сигналу відбувається с періодом в 100 мсек, що дозволяє дослідити зміну напруги, яка загалом має нелінійний характер для значень близьких до границь робочого діапазону.

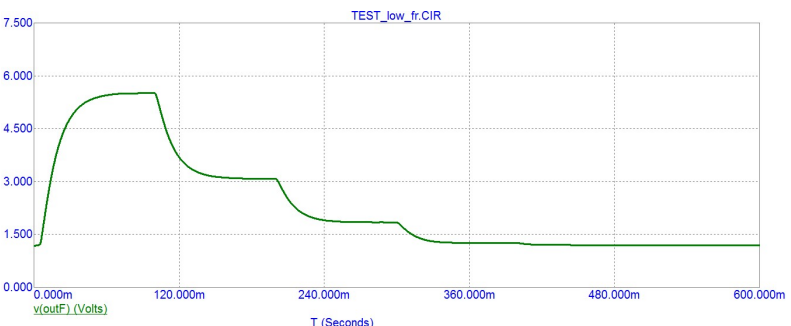

Puc. 8 Часовий аналіз у MicroCap 9: v(outF) - вихідна напруга частотоміру

Дослідження функціонування схеми також було досліджено з використанням частотного аналізу, виконаного 3 функцією Steppingy середовищі MicroCap 9 для величини частоти Fвід 500 до 20000 Гц (рисунок 9).

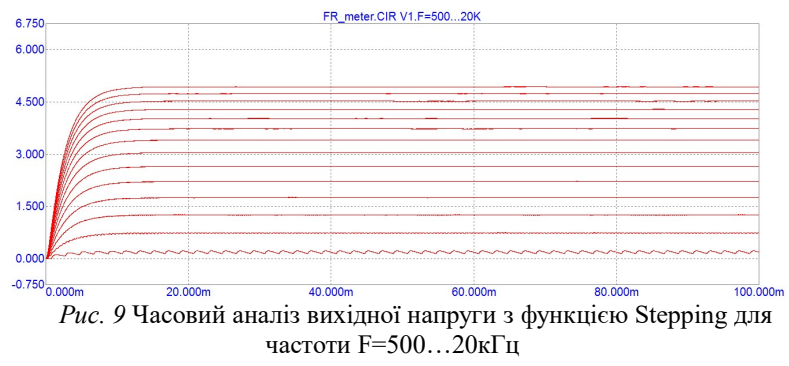

Аналіз показав, що напруга на виході схеми лінійно залежить від частоти вхідного сигналу в діапазоні від 2кГц до 20кГц.

Діапазон вихідних значень та, відповідно, значення площі під кривою на рисунку 9 досягнуті за допомогою джерела фіксованого аналогового сигналу $1,27 \mathrm{~B}$, що забезпечується під'єднанням шунта.
B програмному забезпеченні DipTrace створено схеми 3 підібраними необхідними елементами (рисунок 10).

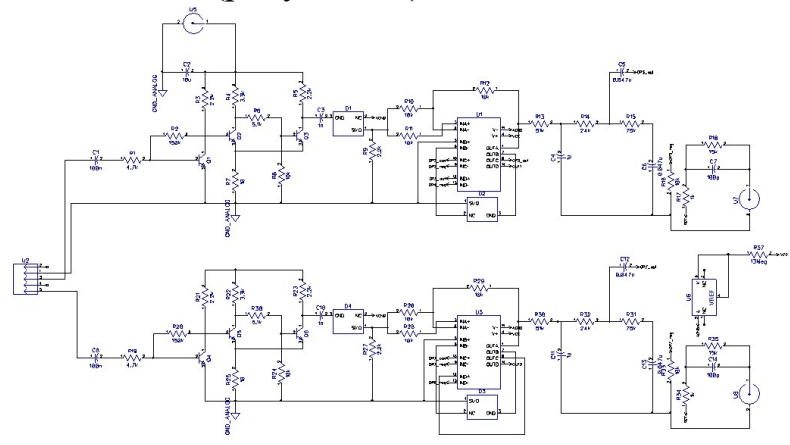

Puc. 10 Електрична схема друкованої плати в DipTrace

При проектуванні були використані операційні підсилювачі AD8567ARUZ чотири у корпусі, діоди MMBD7000 два у корпусі, BNC-гнізда кутові і роз'єм DIN-5 pin (CГ-5).

На рисунку 11 зображена схема трасування відповідної друкованої плати, нижній шар якої відведений під мережу «AGND», тобто аналогову землю схеми.

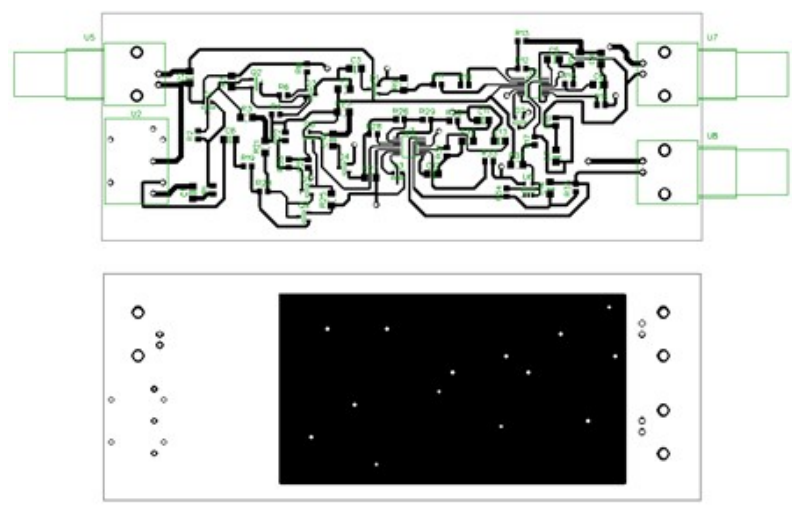

Puc. 11 Схема трасування друкованої плати в DipTrace

Для створення друкованої плати був обраний СМД тип монтажу, розміри резисторів відповідають кодуванню 0805 та 1206, розміри конденсаторів - 1206.

\section{VI. ВИСНОВКИ}

1. Спроектований блок виміру частоти розрахований на два канали для сигналів прямого і зворотного кровотоку в судинах та призначений для виміру середньої швидкості кровотоку.

2. Робочі частоти знаходяться в діапазоні від 200 Гц до 20кГц.

3. Основні складові, на основі яких створена схема аналогового частотоміру: тригер Шмітта, мультивібратор, інтегратор. 
4. Моделювання роботи блоку виміру частоти показало, що існує нелінійна залежність в діапазоні частот від 200 Гц до $2 \kappa \Gamma ц$.

\section{ПЕРЕЛІК ПОСИЛАНЬ}

[1] Satomura, S. (1957). Ultrasonic Doppler method for the inspection of cardiac function. J. acoust. Soc. Am. 29, 1181-1185.

[2] Хилл К., Гаврилов Л. Р., Сарвазян А. П. (ред.). Применение ультразвука в медицине: Физизические основы: Пер. с англ. Мир, 1989. - 404-407 c.

[3] Медицинские приборы. Разработка и применение / Дж. В. Кларк и др. ; ред. Дж. Г. Вебстер. - К. : Медторг, 2004. - 357-366 с.

[4] Амелина М.А., Амелин С.А. Программа схемотехнического моделирования Micro-Сар. Версии 9, 10. Смоленск, НИУ МЭИ, 2012. $-617 \mathrm{c}$.
[5] DipTrace. Руководствопользователя, 2016. - 245 с. (NovarmLtd.).

[6] Основы взаимодействия ультразвука с биологическими объектами: Ультразвук в медицине, ветеринарии и экспериментальной биологии: Учеб. пособие/ Под ред. С. И. Щукина. - М.: Изд-во МГТУ им. Н. Э. Баумана, 2005. - 224 с.: ил. - (Биомедицинская инженерия в техническом университете).

[7] Берестень Н. Ф. Допплеросонография периферических сосудов. Часть II (опытприменения УзИ сканеровфирмы "Медисон" в скрининговых исследованиях) [Електронний ресурс] / Н. Ф. Берестень, А. О. Цыпунов. - Режим доступу до ресурсу: https://www.medison.ru/si/art70.htm.

[8] Меерсон А. М. ИЗМЕРЕНИЕ ЧАСТОТЫ [Електронний ресурс]/ А. М. Меерсо - Режим доступу до ресурсу: http://zpostbox.ru/metody_i_sredstva_izmereniya_chastoty.html

[9] И. А. Нечаев, МассоваяРадиоБиблиотека (МРБ), Выпуск 1172, 1992.

\title{
УДК 612.15
}

\section{СОЗДАНИЕ БЛОКА ИЗМЕРЕНИЯ ЧАСТОТЫ ДЛЯ ДОППЛЕРОВСКОГО УЛЬТРАЗВУКОВОГО РАСХОДОМЕРА}

\author{
Зубков С. В., ст. преподаватель \\ szub284@gmail.com \\ ФечО.О.,студент \\ ardn@meta.ua \\ Факультет биомедицинской инженерии \\ Национальный технический университет \\ «Киевский политехнический інститут шимени Игоря Сикорского» \\ г. Киев, Украина
}

Реферат - Одним из показателей гемодинамики человека является скорость кровотока в сосудах. Показатель скорости кровотока зависит от частоты сокращений сердечной мышиы, количества и качественного состава крови, величины сосудов, артериального давления, возраста и генетических особенностей организма. В настоящее время в диагностике иироко распространено метод ультразвуковой допплерографии. Но, поскольку полученный с помощью допплеровского измерителя скорости сигнал является спектром частот, то актуальным является вопрос создания блока измерения частоты для количественной оценки состояния гемодинамики. В данной работе рассматривается создание и моделирование блока измерения частоты, работающего на частотах от 200 до 20000 Ги, напряжение питания которой 15 В, диапазон значений от 6 до 1,25 B.

Ключевые слова - эффект Допплера, частотомер, скорость кровотока, ультразвук, флоуметрия, допплерография, МісгоСар, гемодинамика. 


\title{
CREATE A FREQUENCY MEASUREMENT UNIT FOR THE DOPPLER ULTRASONIC FLOWMETER
}

\author{
Zubkov.S., Senior Lecturer \\ szub284@gmail.com \\ FechO.O., student \\ ardn@meta.ua \\ Faculty of Biomedical Engineering \\ National Technical University \\ "Igor Sikorsky Kyiv Polytechnic Institute"
}

Kyiv, Ukraine

\begin{abstract}
One of the indicators of human hemodynamics is the rate of blood flow in the blood vessels. The rate of blood flow depends on the frequency of heart muscle contractions, the amount and quality of blood, vascular size, blood pressure, age and genetic features of the body. At present, the method of ultrasound dopplerography has been widely used in diagnosis of widespread use. But since the signal received by the Doppler velocity meter is a spectrum of frequencies, the question of creating a frequency measurement unit for quantifying the state of hemodynamics is relevant. This article describ esthecreation and simulation off requency measurement unit that operatesat frequencies from 200 to 20,000 Hzvoltageby $15 \mathrm{~V}$, valuesrangefrom 6 to $1.25 \mathrm{~V}$.
\end{abstract}

Key words - Doppler effect, frequency meter, blood flow rate, ultrasound, flowmetry, dopplerometry, MicroCap, hemodynamics. 